\title{
Human heterochromatin protein 1 isoforms regulate androgen receptor signaling in prostate cancer
}

\author{
Momoe Itsumi', Masaki Shiota', Akira Yokomizo', Eiji Kashiwagi ', Ario Takeuchi', \\ Katsunori Tatsugami ${ }^{1}$, Junichi Inokuchi', YooHyun Song ${ }^{1}$, Takeshi Uchiumi ${ }^{2}$ and \\ Seiji Naito' \\ ${ }^{1}$ Departments of Urology and ${ }^{2}$ Clinical Chemistry and Laboratory Medicine, Graduate School of Medical Sciences, \\ Kyushu University, 3-1-1 Maidashi, Higashi-ku, Fukuoka 812-8582, Japan
}

Correspondence should be addressed to A Yokomizo

Email

yokoa@ uro.med.kyushu-u.ac.jp

\begin{abstract}
Androgen receptor (AR) signaling is critical for the tumorigenesis and development of prostate cancer, as well as the progression to castration-resistant prostate cancer. We previously showed that the heterochromatin protein 1 (HP1) $\beta$ isoform plays a critical role in transactivation of AR signaling as an AR coactivator that promotes prostate cancer cell proliferation. However, the roles of other HP1 isoforms, HP1 $\alpha$ and HP1 $\gamma$, in AR expression and prostate cancer remain unclear. Here, we found that knockdown of $H P 1 \gamma$, but not $H P 1 \alpha$, reduced AR expression and cell proliferation by inducing cell cycle arrest at G1 phase in LNCaP cells. Conversely, overexpression of full-length HP1 $\alpha$ and its C-terminal deletion mutant increased AR expression and cell growth, whereas overexpression of HP1 $\gamma$ had no effect. Similarly, HP1 $\alpha$ overexpression promoted 22Rv1 cell growth, whereas HP1 $\gamma$ knockdown reduced the proliferation of CxR cells, a castration-resistant LNCaP derivative. Taken together, HP1 isoforms distinctly augment AR signaling and cell growth in prostate cancer. Therefore, silencing of $H P 1 \beta$ and $H P 1 \gamma$ may be a promising therapeutic strategy for treatment of prostate cancer.
\end{abstract}

Key Words

- androgen receptor

- castration-resistant prostate cancer

- heterochromatin protein 1

- prostate cancer

\section{Introduction}

Prostate cancer is the most common non-cutaneous cancer and the second leading cause of cancer-related death of men in developed countries (Siegel et al. 2012). Prostate-specific antigen (PSA) screening has improved early detection of prostate cancer and has recently been proved to reduce the risk of death by prostate cancer (Schröder et al. 2009, 2012, Hugosson et al. 2010, Andriole et al. 2012). However, a quarter of early-stage prostate cancer patients still suffer from relapse of the disease despite surgical and/or radiation therapy. In addition, many patients with prostate cancer are diagnosed at an
Journal of Molecular

Endocrinology

(2013) 50, 401-409 advanced stage of the disease. Although most prostate cancers are originally androgen dependent and respond well to androgen-deprivation therapy (ADT), they eventually become castration-resistant prostate cancer (CRPC) during ADT, which is thought to remain dependent on androgen receptor (AR) signaling for growth in a low-androgen milieu (Ryan \& Tindall 2011).

The AR is a member of the class I subgroup of the nuclear receptor superfamily and a ligand-dependent transcription factor. The androgen/AR signaling pathway is thought to play a central role in the development and 
progression of prostate cancer including CRPC. The mammalian heterochromatin protein 1 (HP1) family plays a critical role in a variety of cellular processes including centromere stability, telomere stability, regulation of gene expression, DNA repair, cellular senescence, and cancer progression through their activities in DNA and its interacting proteins (Zhang \& Adams 2007, Dialynas et al. 2008, Ayoub et al. 2009). Three mammalian HP1 isoforms, HP1 $\alpha$ (CBX5), HP1 $\beta$ (CBX1),

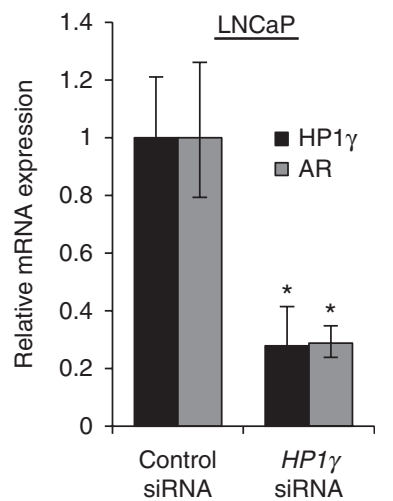

B

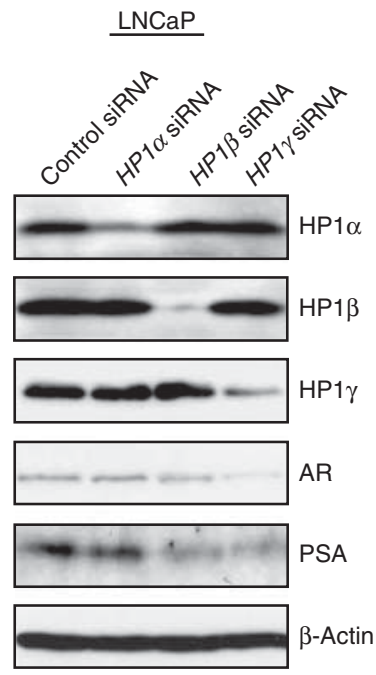

C

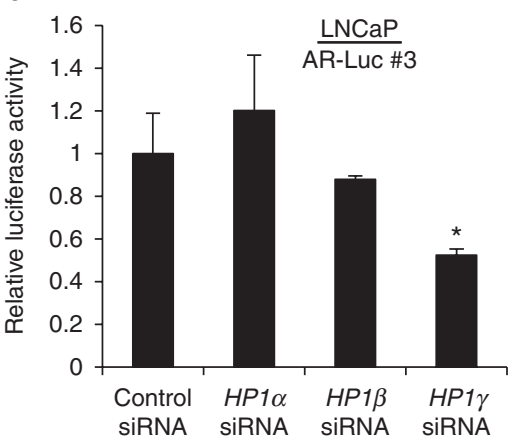

http://jme.endocrinology-journals.org DOI: 10.1530/JME-13-0024
(๑) 2013 Society for Endocrinology Printed in Great Britain and HP1 $\gamma(\mathrm{CBX} 3)$, have been identified in humans. Each of these heterochromatins contains two conserved domains, a chromodomain (CD) interacting with dimethylated Lys9 of histone $\mathrm{H} 3$ and a chromoshadow domain (CSD) interacting with the PxVxL motif of its partner, which are separated by a flexible hinge region (Kwon \& Workman 2011). HP1 isoforms are known to exhibit different subnuclear localizations in interphasic nuclei. HP1 $\alpha$ is mainly centromeric, HP1 $\beta$ is also centromeric, but to a lesser extent, and HP1 $\gamma$ is located in both euchromatic and heterochromatic compartments (Dialynas et al. 2007). HP1 heteromers are associated with nucleosomal core histones (Zhao et al. 2000) and reduce the transcription of nearby promoters when tethered to DNA (Cryderman et al. 1999). Furthermore, HP1 isoforms in mice and humans interact directly with the transcriptional corepressor TIF $\beta$, supporting the hypothesis that HP1 isoforms play a role in gene silencing (Nielsen et al. 1999). However, it has been recently reported that HP1 isoforms may work at euchromatic regions and as a gene activator despite their name, localization, and suggested function (Piacentini et al. 2003, Hediger \& Gasser 2006, de Wit et al. 2007, Fanti \& Pimpinelli 2008). On the other hand, in several cancers, HP1 $\alpha$ expression has been reported to be decreased compared with that in the corresponding normal tissues (Pomeroy et al. 2002, Wasenius et al. 2003). In addition, reduction of HP1 $\alpha$ expression has been observed in various cancers including cancers undergoing progression (Dialynas et al. 2008). However, several recent reports show that HP1 isoforms are upregulated in various tumor tissues, compared with

Figure 1

$H P 1 \gamma$ knockdown transcriptionally reduces AR expression. (A) LNCaP cells were transfected with $40 \mathrm{nM}$ of the indicated siRNA. At $72 \mathrm{~h}$ posttransfection, quantitative real-time PCR was performed using the indicated primers and probes. The target transcript level was normalized to the GAPDH transcript level. All values represent at least three independent experiments. The level of each transcript from cells transfected with control siRNA was defined as 1 . Boxes, mean; bars, \pm s.D. ${ }^{*} P<0.05$ (compared with control siRNA). (B) LNCaP cells were transfected with $40 \mathrm{nM}$ of the indicated siRNA. At $72 \mathrm{~h}$ post-transfection, whole cell extracts were subjected to western blotting using the indicated antibodies. (C) LNCaP cells were transfected with $0.5 \mu \mathrm{g} / \mathrm{ml}$ of the AR-Luc \#3 reporter plasmids, $20 \mathrm{nM}$ of the indicated siRNA, and $0.05 \mu \mathrm{g} / \mathrm{ml} \mathrm{pRL-TK}$ and then incubated for $48 \mathrm{~h}$. Firefly luciferase activity was normalized to the corresponding Renilla luciferase activity. All values represent at least three independent experiments. The luciferase activity in cells transfected with control siRNA was defined as 1 . Boxes, mean; bars, \pm s.D. ${ }^{*} P<0.05$ (compared with control siRNA).

Published by Bioscientifica Ltd. 
those in normal tissues, and increases according to tumor progression (De Koning et al. 2009, Takanashi et al. 2009).

Recently, we reported that HP1 $\beta$ plays a tumorpromoting role in prostate cancer through transactivation of AR signaling as an AR coactivator that promotes prostate cancer cell proliferation (Shiota et al. 2010a). However, except for HP1 $\beta$, the functions of the HP1 family in AR signaling and prostate cancer cell proliferation remain unknown. Additionally, the roles of each domain of HP1 in AR signaling and cancer cell proliferation remain unclear. Therefore, the aim of this study was to determine the functions of the HP1 family in association with the AR and prostate cancer cell proliferation.

\section{Materials and methods}

\section{Cell culture}

LNCaP and 22Rv1 human prostate cancer cells were cultured in RPMI 1640 (Invitrogen) containing 10\% fetal bovine serum. Passage 10-40 LNCaP cells were used in experiments. A castration-resistant derivative of $\mathrm{LNCaP}$ cells, LNCaP-CxR cells (referred to as CxR cells), was established and maintained as described previously (Shiota et al. 2010b). The cell lines were maintained at $37^{\circ} \mathrm{C}$ with $5 \% \mathrm{CO}_{2}$.

\section{Antibodies}

Antibodies against the AR (sc-815) and green fluorescent protein (GFP) (sc-8334) were purchased from Santa Cruz Biotechnology. Anti-HP1 $\alpha$ (\#2623) and anti-HP1 $\gamma$ (\#2619) antibodies were purchased from Cell Signaling Technology (Cambridge, MA, USA). Anti-HP1ß (ab49938), anti-PSA, anti- $\beta$-actin, and anti-HA antibodies were purchased from Abcam (Cambridge, MA, USA), Epitomics (Burlingame, CA, USA), Sigma, and Roche Applied Science respectively.

\section{Plasmid construction}

The AR reporter plasmid (AR-Luc \#3) was constructed as described previously (Shiota et al. 2010b). Construction of pCMV-HA-HP1 $\alpha$, pCMV-HA-HP1 $\beta$, and pCMV-HA-HP $1 \gamma$ plasmids expressing N-terminal HA-tagged HP1 $\alpha$, HP1 $\beta$, and $\mathrm{HP} 1 \gamma$ proteins respectively has been described previously (Shiota et al. 2010a). To prepare GFP-HP1 $\alpha$, GFP-HP1 $\beta$, and GFP-HP1 $\gamma$ plasmids expressing N-terminal GFP-tagged HP1 $\alpha$, HP1 $\beta$, and HP1 $\gamma$ proteins, respectively, EcoRI-SalI fragments of $H P 1 \alpha, H P 1 \beta$, and $H P 1 \gamma$ cDNAs from pCMV-HA-HP1 $\alpha$, pCMV-HA-HP1 $\beta$, and pCMVHA-HP1 $\gamma$ were inserted into the EcoRI-Sall sites of pEGFP plasmids (C3; Invitrogen) respectively. The pCMV-HA-HP1 $\beta \Delta C$ (aa 1-116) plasmid expressing the $\mathrm{N}$-terminal HA-tagged C-terminally deleted HP1 $\beta$ protein was created by deletion of the XhoI fragment from the pCMV-HA-HP1 $\beta$ plasmid. Other deletion mutants were constructed from GFP-HP1 $\alpha$, GFP-HP1 $\beta$, GFP-HP1 $\gamma$, and pCMV-HA-HP1 $\beta$ plasmids using a KOD Mutagenesis Kit (Toyobo, Osaka, Japan) with the following primer pairs: 5'-GTCGACGGTACCGCGGGCCCGGGAT-3' and $5^{\prime}$-ATCATTGCTCTGCTCTCTCTTTTTTTTAG-3' for GFP-HP1 $\alpha \Delta C$ (aа 1-112); 5'-ATCGCTCGGGGCTTTGAGAGAGGAC-3' and 5'-AATTCGAAGCTTGAGCTCGAGATCTG-3' for GFP-HP1 $\alpha \Delta \mathrm{N}$ (aa 113-190); 5'-GGTTTGGAGCCGGAGCGGATTATTG-3' and 5'-GTACTTGTACAGCTCGTCCATGCCG-3' for GFP-HP1 $\beta \Delta \mathrm{N}$ (aa 116-185); $5^{\prime}$-GTCGACGGTACCGCGGGCCCGGGAT-3' and $5^{\prime}$-AGCAGCATCTCTTTTCTTCTTTGAT-3' for GFP-HP1 $\gamma \Delta \mathrm{C}$ (aa 1-110); 5'-GCTGACAAACCAAGAGGATTTGCCAG-3' and $5^{\prime}$-AATTCGAAGCTTGAGCTCGAGATCTG-3' for GFP-HP1 $\gamma \Delta \mathrm{N}$ (aa 111-182); and 5'-GGTTTGGAGCCGGAGCGGATTATTG-3' and 5'-AAGAGCGTAATCTGGAACATCGTATGGG-3' for pCMV-HA-HP1 $\beta \Delta \mathrm{N}$ (aa 116-185). The integrity of mutated plasmids was confirmed by sequencing. To construct pCMV-HA-HP1 $\alpha \Delta \mathrm{C}$ (aa 1-112), pCMV-HA-HP1 $\alpha \Delta \mathrm{N}$ (aa 113-190), pCMV-HA-HP1 $\gamma \Delta \mathrm{C}$ (aa 1-110), and pCMV-HA-HP1 $\gamma \Delta \mathrm{N}$ (aa 111-182) plasmids, XhoI-Sall fragments from GFP-HP1 $\alpha \Delta \mathrm{C}$, GFP-HP1 $\alpha \Delta \mathrm{N}$, GFP-HP1 $\gamma \Delta \mathrm{C}$, and GFP-HP1 $\gamma \Delta \mathrm{N}$ were inserted into XhoI-Sall sites of pCMV-HA plasmids respectively.

\section{Western blotting}

The preparation of whole cell extracts and western blotting were performed as described previously (Shiota et al. 2010a,b, 2011a,b).

\section{Knockdown analysis using siRNA}

Knockdown analysis using siRNA was performed as described previously (Shiota et al. 2010a,b, 2011a,b). Briefly, the following double-stranded RNA oligonucleotides were commercially generated: 5'-CAUAUCCUGAGGAUGCGGATT-3' (sense) and 5'-UCCGCAUCCUCAGGAUAUGTT- ${ }^{\prime}$ (antisense) for $H P 1 \alpha$ siRNA (Sigma); 5'-AUUUCAUCAGGAACAUGAGCUCUCC-3' (sense) and 5'-GGAGAGCUCAUGUUCCUGAUGAAAU-3' (antisense) for HP1 $\beta$ siRNA (Invitrogen); and $5^{\prime}$-CCAAGAGGAUUUGCCAGAGTT-3' (sense) and

Published by Bioscientifica Ltd. 

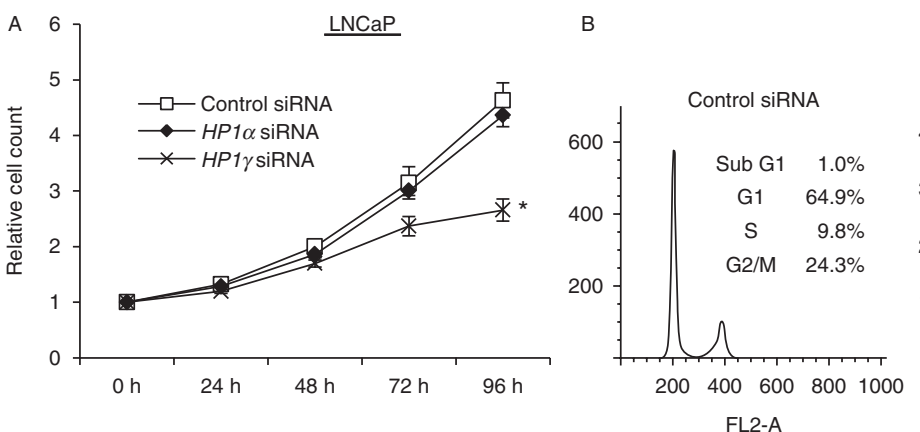
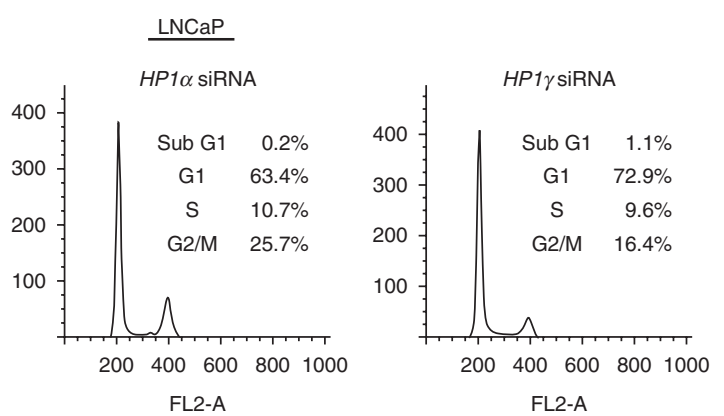

Figure 2

$H P 1 \gamma$ silencing reduces prostate cancer cell proliferation by inducing cell cycle arrest at G1 phase. (A) LNCaP cells were transfected with $40 \mathrm{nM}$ of the indicated siRNA and then cultured. The number of cells was counted the indicated times. The results were normalized to the number of cells at $0 \mathrm{~h}$. All values represent at least three independent experiments. Boxes, mean;

5'-CUCUGGCAAAUCCUCUUGGTT-3' (antisense) for $H P 1 \gamma$ siRNA (Sigma). LNCaP and CxR cells were transfected with the indicated amounts of siRNA using Lipofectamine 2000 (Invitrogen) according to the manufacturer's protocol.

\section{Luciferase reporter assay, RNA isolation, RT-PCR and quantitative real-time PCR, cell proliferation assay, and flow cytometry}

These procedures were performed as described previously (Shiota et al. 2010a,b, 2011a,b).

\section{Statistical analysis}

A $t$-test was used for statistical analysis. $P$ values $<0.05$ were considered to be statistically significant.

\section{Results}

\section{$H P 1 \gamma$ knockdown transcriptionally reduces AR expression}

First, we functionally analyzed AR expression by knockdown using HP1-specific siRNAs in LNCaP prostate cancer cells. HP1 $\beta$ has been shown to affect PSA expression but not AR expression as an AR coactivator in our previous study (Shiota et al. 2010a). Similarly, HP1 $\alpha$ knockdown exerted no effect on AR expression. On the other hand, $H P 1 \gamma$ silencing reduced the $A R$ transcript level (Fig. 1A). Consistently, AR protein expression was also suppressed by $H P 1 \gamma$ silencing (Fig. 1B), and also major AR-target gene PSA expression was suppressed by $H P 1 \beta$ and $H P 1 \gamma$ knockdown. In addition, using an AR reporter bars, \pm s.D. ${ }^{*} P<0.05$ (compared with control siRNA). (B) LNCaP cells were transfected with $40 \mathrm{nM}$ of the indicated siRNA and then cultured. At $72 \mathrm{~h}$ post-transfection, cells were stained with propidium iodide and analyzed by flow cytometry. The cell cycle distribution is shown in the upper right of each graph.

plasmid (AR-Luc \#3) in a luciferase reporter assay, we found reduced luciferase activity by $H P 1 \gamma$ silencing, indicating that $H P 1 \gamma$ knockdown downregulates $A R$ transcription (Fig. 1C).
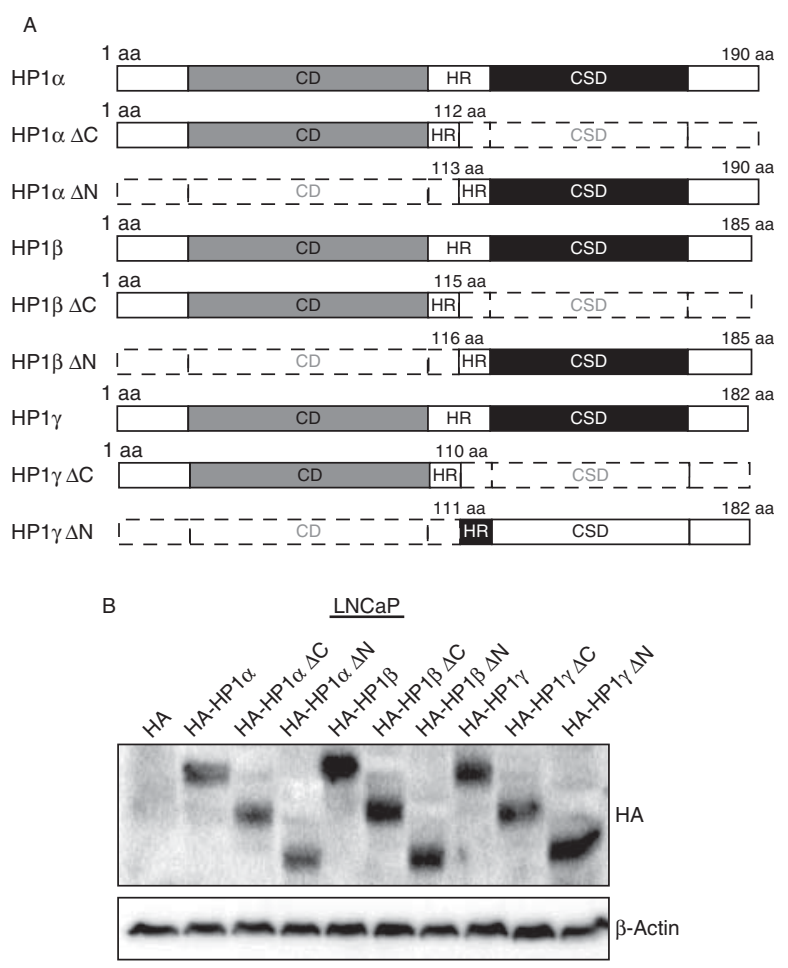

Figure 3

Expression of the HP1 family by expression plasmids. (A) Schematic representation of full-length and deletion-mutant HP1 isoforms. (B) Whole cell extracts of LNCaP cells transfected with $1 \mu \mathrm{g} / \mathrm{ml}$ of the indicated expression plasmid and then incubated for $48 \mathrm{~h}$ were subjected to western blotting using the indicated antibodies.

Published by Bioscientifica Ltd. 
$H P 1 \gamma$ silencing reduces prostate cancer cell proliferation by inducing cell cycle arrest at G1 phase

Next, we investigated the effects of HP1 isoforms on prostate cancer cell proliferation by HP1 knockdown. Previously, we showed that HP1 $\beta$ knockdown reduces prostate cancer proliferation by suppressing AR transactivation (Shiota et al. 2010a). Here, we examined the effect of HP1 $\alpha$ and HP1 $\gamma$ on cell proliferation. The data showed that HP1 $\gamma$ silencing reduced LNCaP cell proliferation, whereas HP1 $\alpha$ knockdown did not affect cell
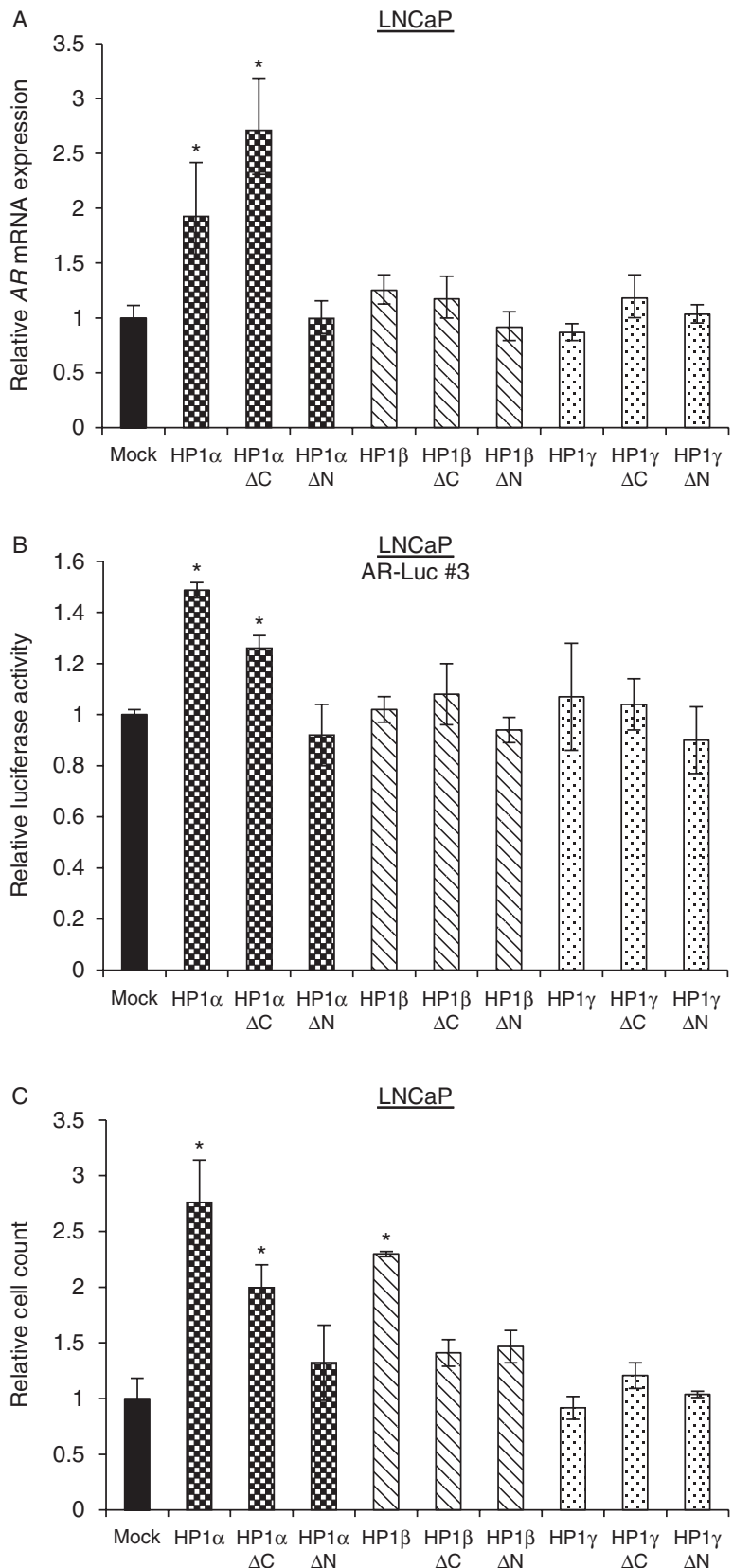

http://jme.endocrinology-journals.org DOI: 10.1530/JME-13-0024

2013 Society for Endocrinology Printed in Great Britain growth (Fig. 2A). To reveal the mechanism of cell growth retardation by $H P 1 \gamma$ silencing, we performed cell cycle analysis using flow cytometry. As shown in Fig. 2B, HP1 $\gamma$ suppression resulted in an accumulation of LNCaP cells in G1 phase, indicating cell growth suppression by inducing cell cycle arrest at G1 phase.

\section{Overexpression of HP1 affects AR expression and prostate cancer cell proliferation}

Next, we examined the effect of HP1 overexpression on AR expression and prostate cancer cell proliferation. To overexpress the HP1 family, we constructed HA-tagged HP1 expression plasmids, as well as deletion mutants to investigate the roles of the CD and CSD (Fig. 3A). The expression of HA-tagged full-length and deletion-mutant HP1 isoforms was confirmed by western blotting using whole cell extracts (Fig. 3B). Next, $A R$ transcript levels were examined after overexpression of various HP1 isoforms. As shown in Fig. 4A, overexpression of HP1 $\alpha$ and HP1 $\alpha \Delta \mathrm{C}$ increased the $A R$ transcript level, which was supported by the results of luciferase reporter assays using an AR reporter plasmid (Fig. 4B). Furthermore, cell proliferation was enhanced by overexpression of HP1 $\beta$, which was in agreement with our previous report, as well as full-length HP1 $\alpha$ and HP1 $\alpha \Delta \mathrm{C}$ (Fig. 4C).

Furthermore, we examined the role of the HP1 family in prostate cancer cell proliferation using another AR-expressing prostate cancer cell line, 22Rv1. Expression of GFP-HP1 isoforms in 22Rv1 cells was confirmed by western blotting as shown in Fig. 5A. After overexpression

\section{Figure 4}

Overexpression of HP1 isoforms affects AR expression and LNCaP cell proliferation. (A) LNCaP cells were transfected with $1 \mu \mathrm{g} / \mathrm{ml}$ of the indicated expression plasmid. At $72 \mathrm{~h}$ post-transfection, quantitative real-time PCR was performed using the indicated primers and probes. The target transcript level was normalized to the GAPDH transcript level. All values represent at least three independent experiments. The level of each transcript from cells transfected with mock plasmid was defined as 1 . Boxes, mean; bars, \pm s.D. ${ }^{*} P<0.05$ (compared with Mock). (B) LNCaP cells were transfected with $0.5 \mu \mathrm{g} / \mathrm{ml}$ of the AR-Luc \#3 reporter plasmids, $0.5 \mu \mathrm{g} / \mathrm{ml}$ of the indicated expression plasmid, and $0.05 \mu \mathrm{g} / \mathrm{ml} \mathrm{pRL-TK}$ and then incubated for $48 \mathrm{~h}$. Firefly luciferase activity was normalized to the corresponding Renilla luciferase activity. All values represent at least three independent experiments. The luciferase activity in cells transfected with mock plasmid was defined as 1 . Boxes, mean; bars, \pm s.D. ${ }^{*} P<0.05$ (compared with Mock). (C) LNCaP cells were transfected with $1 \mu \mathrm{g} / \mathrm{ml}$ of the indicated expression plasmid and then cultured. The number of cells was counted at $72 \mathrm{~h}$. The results were normalized to the number of cells at $0 \mathrm{~h}$. All values represent at least three independent experiments. Boxes, mean; bars, \pm s.D. ${ }^{*} P<0.05$ (compared with Mock).

Published by Bioscientifica Ltd. 
A
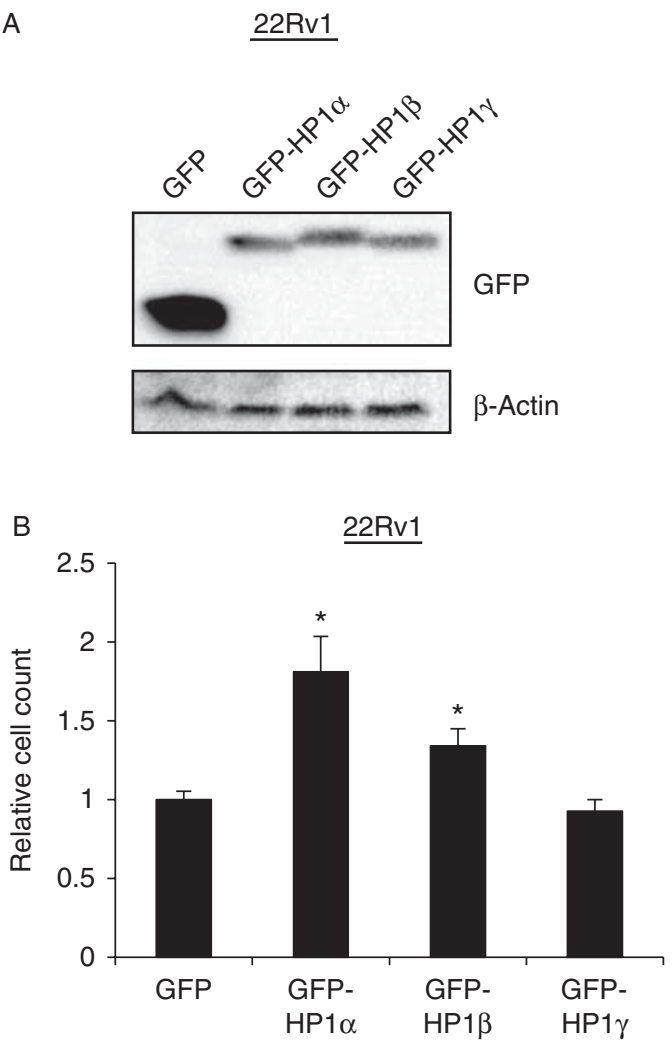

Figure 5

Overexpression of HP1 isoforms affects 22Rv1 cell proliferation. (A) Whole cell extracts of LNCaP cells transfected with $1 \mu \mathrm{g} / \mathrm{ml}$ of the indicated expression plasmid and then incubated for $48 \mathrm{~h}$ were subjected to western blotting using the indicated antibodies. (B) 22Rv1 cells were transfected with $1 \mu \mathrm{g} / \mathrm{ml}$ of the indicated expression plasmid and then cultured. The number of cells was counted at $72 \mathrm{~h}$. The results were normalized to the number of cells at $0 \mathrm{~h}$. All values represent at least three independent experiments. Boxes, mean; bars, \pm s.D. ${ }^{*} P<0.05$ (compared with GFP).

of the HP1 family, 22Rv1 cell proliferation was augmented by HP1 $\beta$ and more strongly by HP1 $\alpha$ (Fig. 5B).

\section{HP1 expression and function in CRPC}

To investigate the relevance of the HP1 family in CRPC, we compared the expression of HP1 isoforms between LNCaP cells and its castration-resistant derivative, CxR cells. We found that HP1 $\beta$ expression was elevated in CxR cells, as well HP1 $\beta$ knockdown resulted in decreases of PSA expression and CxR cell proliferation (Shiota et al. $2010 a$ ). In addition, HP1 $\alpha$ was upregulated, while HP1 $\gamma$ expression was comparable in CxR cells (Fig. 6A). Next, we examined the effect of HP1 knockdown on AR expression. As shown in Fig. 6B, AR expression was also reduced in CxR cells by $H P 1 \gamma$ silencing, which was similar to that in LNCaP cells (Fig. 6B). As a result, HP1 $\gamma$ knockdown also suppressed CxR cell proliferation (Fig. 6C).

\section{Discussion}

Classically, the HP1 family has been thought to have suppressive effects on cancer growth and progression. For example, it has been reported that HP1 $\alpha$ expression is reduced in invasive human breast cancer cell lines compared with that in non-invasive breast cancer cell lines (Kirschmann et al. 1999). Overexpression of HP1 $\alpha$ in invasive cells reduces their in vitro invasive potential (Kirschmann et al. 2000), whereas reducing its expression increases their invasive potential (Norwood et al. 2006). These data suggest that HP $1 \alpha$ acts as a progression suppressor in breast cancer cells. In addition, reduction of HP1 $\alpha$ expression has been observed in metastatic colon cancer cell lines compared with that in non-metastatic cell lines (Ruginis et al. 2006), and in papillary thyroid
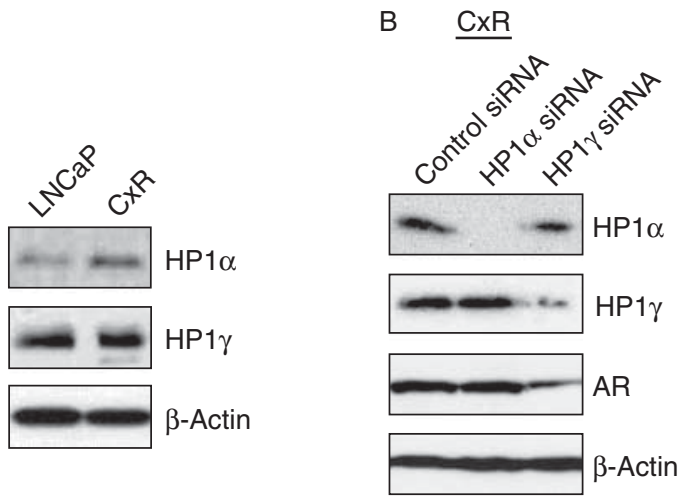

C

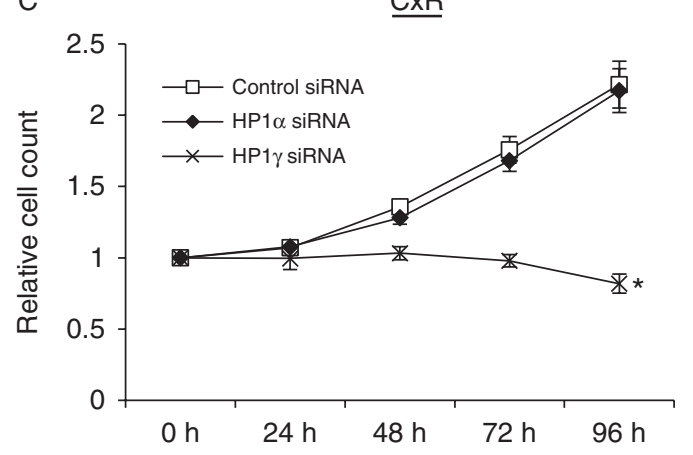

Figure 6

HP1 expression and function in CRPC. (A) Whole cell extracts of LNCaP and CxR cells were subjected to western blotting using the indicated antibodies. (B) CxR cells were transfected with $40 \mathrm{nM}$ of the indicated siRNA. At $72 \mathrm{~h}$ post-transfection, whole cell extracts were subjected to western blotting using the indicated antibodies. (C) CxR cells were transfected with $40 \mathrm{nM}$ of the indicated siRNA and then cultured. The number of cells was counted at the indicated times. The results were normalized to the number of cells at $0 \mathrm{~h}$. All values represent at least three independent experiments. Boxes, mean; bars, \pm s.D. ${ }^{\star} P<0.05$ (compared with control siRNA).

Published by Bioscientifica Ltd. 
carcinoma compared with that in normal thyroid tissue (Wasenius et al. 2003), as reviewed by Dialynas et al. (2008). In line with this finding, HP1 isoforms have been reported to be downregulated in mouse prostate cancer (Shapiro et al. 2008).

However, recent findings suggest a conceptual shift from a suppressive to promoting role of the HP1 family in cancers. For example, HP1 $\gamma$ has been shown to be positive in all cancer tissues but is not positive in the matching normal epithelium (Takanashi et al. 2009). Consistently, suppression of $\mathrm{HP} 1 \gamma$ expression restrains the proliferation of various cancer cell types, but not that of normal cells, suggesting that HP1 $\gamma$ is a promising therapeutic target (Takanashi et al. 2009). Similarly, HP1 $\alpha$ expression is upregulated in various tumor tissues in contrast to the corresponding normal tissues without detectable HP1 $\alpha$ expression, as well as in highly malignant breast cancers with poor patient survival (De Koning et al. 2009). In addition, HP1-related methyltransferase G9a has been reported to promote lung cancer invasion and metastasis (Chen et al. 2010). In addition, we have recently shown that HP1 $\beta$ is upregulated with an increased Gleason score in prostate cancer (Shiota et al. 2010a).

Takanashi et al. (2009) reported that re-expression of $\mathrm{HP} 1 \gamma$ by overexpression maintains human pre-adipocytes in an undifferentiated state even with HP1 $\gamma$ suppression by a differentiation inducer, suggesting a role of HP $1 \gamma$ re-expression in maintaining the undifferentiated state of cells. Similarly, the HP1 family has been shown to be downregulated in differentiated blood lymphocytes compared with that in their undifferentiated precursors (Gilbert et al. 2003, Baxter et al. 2004, Ritou et al. 2007). Taken together, these results indicate that loss of $\mathrm{HP} 1 \gamma$ expression is essential for differentiation, suggesting a function as a safety mechanism for the transition to cellular differentiation. Consistently, our results showed that $H P 1 \gamma$ knockdown suppressed prostate cancer cell growth, whereas overexpression of $\mathrm{HP} 1 \gamma$ showed no significant effect on cell proliferation. This result indicates that HP1 $\gamma$ overexpression is unnecessary for cell proliferation at least in our experimental setting, although it is necessary to maintain cell cycling.

By contrast, HP1 $\alpha$ overexpression promoted prostate cancer cell proliferation, whereas HP1 $\alpha$ silencing exerted no apparent suppressive effect on cell growth, which is consistent with a previous report showing that HP1 $\alpha$ knockdown does not affect cell proliferation (Norwood et al. 2006) or cell cycle distribution (De Koning et al. 2009). Furthermore, the proliferation-promoting role of $\mathrm{HP} 1 \alpha$ is consistent with previous findings indicating that oncogenic E2F (Weinmann et al. 2002, Oberley et al. 2003) and myc (Li et al. 2003, Kim et al. 2008) transcription factors positively regulate HP1 $\alpha$ expression. These results appear to indicate a role of HP1 $\alpha$ in cell proliferation as a growth factor, which can be substituted by other factors.

In addition to the tumor-promoting role of HP1 proteins, we revealed a role of HP1 isoforms in AR singling. We previously reported the role of $\mathrm{HP} 1 \beta$ as an AR coactivator in prostate cancer. In addition, we revealed the role of HP1 $\alpha$ and HP1 $\gamma$ in AR expression: HP1 $\alpha$ overexpression induced AR expression while $H P 1 \gamma$ knockdown reduced AR expression, by overexpression and knockdown methods respectively. Although these findings were not recapitulated by reversing the expression of HP1 $\alpha$ and HP1 $\gamma$, they were correlated with cell proliferation, which was consistent with the role of the AR in cell proliferation of prostate cancer. As $H P 1 \beta$ knockdown did not affect cell proliferation in AR-negative PC-3 cells (Shiota et al. 2010a), AR signaling may mediate the effect on cell proliferation by HP1, especially HP1 $\beta$.

Overexpression of CD- or CSD-deleted $\mathrm{HP} 1 \gamma$ partially exerted a similar effect as that of full-length $\mathrm{HP} 1 \gamma$, indicating that both the CD and CSD of HP1 $1 \gamma$ can retain partial activity of full-length HP1 $\gamma$ (Takanashi et al. 2009). Similarly, our study showed that HP1 $\alpha \Delta \mathrm{C}$ exerted similar effects on AR signaling and prostate cancer cell proliferation as those of full-length HP1 $\alpha$, suggesting a supporting or compensating role of the CD of HP1 $\alpha$ for full-length HP1 $\alpha$.

Intriguingly, HP1 isoforms are thought to be implicated in the DNA damage response induced by various toxins including oxidative stress (Dinant \& Luijsterburg 2009). HP1 is recruited to damaged regions of DNA and facilitates the DNA repair pathway activated by oxidative lesions (Zarebski et al. 2009). These findings are interesting because it has been shown that oxidative stress is induced by androgen deprivation (Shiota et al. 2010b) and is increased in CRPC (Shigemura et al. 2007), which is consistent with upregulation of HP1 $\alpha$ and HP1 $\beta$ in CRPC cells and their promoting role in AR signaling and cell proliferation in prostate cancer. These results indicate that HP1 isoforms participate in cross talk between oxidative stress and AR signaling in prostate cancer. Moreover, HP1 isoforms may augment therapeutic effects by genotoxic anticancer therapy that exerts oxidative stress, which is supported by the finding that a higher sensitivity to ionizing radiation is also observed in HP1 $\alpha$ - or HP1 $\beta$-overexpressing cells (Sharma et al. 2003).

In conclusion, HP1 isoforms distinctly promote AR signaling and prostate cancer growth, which may

Published by Bioscientifica Ltd. 
contribute to progression to CRPC. Therefore, silencing of HP1 $\beta$ and HP1 $\gamma$ appears to be a promising therapeutic strategy for treatment of prostate cancer.

\section{Declaration of interest}

The authors declare that there is no conflict of interest that could be perceived as prejudicing the impartiality of the research reported.

\section{Funding}

This work was supported in part by Kakenhi grants $(22591769,24890160)$ from The Ministry of Education, Culture, Sports, Science, and Technology of Japan (MEXT), Japan; Research Promotion Grant from The Tokyo Biochemical Research Foundation, Japan; Medical Research Promotion Grant from Takeda Science Foundation, Japan; and Research Promotion Grant from The Uehara Memorial Foundation, Japan.

\section{Acknowledgements}

The authors thank Dr Dongchon Kang (Kyushu University, Fukuoka, Japan) for helping with quantitative real-time PCR and flow cytometry, Edanz Group Japan for editorial assistance, as well as Noriko Hakoda and Eriko Gunshima for their technical assistance. The authors would also like to acknowledge the technical expertise of the Support Center for Education and Research, Kyushu University.

\section{References}

Andriole GL, Crawford ED, Grubb RL III, Buys SS, Chia D, Church TR, Fouad MN, Isaacs C, Kvale PA, Reding DJ et al. 2012 Prostate cancer screening in the randomized prostate, lung, colorectal, and ovarian cancer screening trial: mortality results after 13 years of follow-up. Journal of the National Cancer Institute 104 125-132. (doi:10.1093/ jnci/djr500)

Ayoub N, Jeyasekharan AD \& Venkitaraman AR 2009 Mobilization and recruitment of HP1: a bimodal response to DNA breakage. Cell Cycle 8 2945-2950.

Baxter J, Sauer S, Peters A, John R, Williams R, Caparros ML, Arney K, Otte A, Jenuwein T, Merkenschlager M et al. 2004 Histone hypomethylation is an indicator of epigenetic plasticity in quiescent lymphocytes. EMBO Journal 23 4462-4472. (doi:10.1038/sj.emboj.7600414)

Chen MW, Hua KT, Kao HJ, Chi CC, Wei LH, Johansson G, Shiah SG, Chen PS, Jeng YM, Cheng TY et al. 2010 H3K9 histone methyltransferase G9a promotes lung cancer invasion and metastasis by silencing the cell adhesion molecule Ep-CAM. Cancer Research 70 7830-7840. (doi:10.1158/0008-5472.CAN-10-0833)

Cryderman DE, Tang H, Bell C, Gilmour DS \& Wallrath LL 1999 Heterochromatic silencing of Drosophila heat shock genes acts at the level of promoter potentiation. Nucleic Acids Research 27 3364-3370. (doi:10.1093/nar/27.16.3364)

De Koning L, Savignoni A, Boumendil C, Rehman H, Asselain B, Sastre-Garau X \& Almouzni G 2009 Heterochromatin protein $1 \alpha$ : a hallmark of cell proliferation relevant to clinical oncology. $E M B O$ Molecular Medicine 1 178-191. (doi:10.1002/emmm.200900022)

Dialynas GK, Terjung S, Brown JP, Aucott RL, Baron-Luhr B, Singh PB \& Georgatos SD 2007 Plasticity of HP1 proteins in mammalian cells. Journal of Cell Science 120 3415-3424. (doi:10.1242/jcs.012914)

Dialynas GK, Vitalini MW \& Wallrath LL 2008 Linking heterochromatin protein 1 (HP1) to cancer progression. Mutation Research 647 13-20. (doi:10.1016/j.mrfmmm.2008.09.007)
Dinant C \& Luijsterburg MS 2009 The emerging role of HP1 in the DNA damage response. Molecular and Cellular Biology 29 6335-6340. (doi:10.1128/MCB.01048-09)

Fanti L \& Pimpinelli S 2008 HP1: a functionally multifaceted protein. Current Opinion in Genetics \& Development 18 169-174. (doi:10.1016/ j.gde.2008.01.009)

Gilbert N, Boyle S, Sutherland H, de Las Heras J, Allan J, Jenuwein T \& Bickmore WA 2003 Formation of facultative heterochromatin in the absence of HP1. Insulation of the chicken beta-globin chromosomal domain from a chromatin-condensing protein, MENT. EMBO Journal 22 5540-5550. (doi:10.1093/emboj/cdg520)

Hediger F \& Gasser SM 2006 Heterochromatin protein 1, don't judge the book by its cover!. Current Opinion in Genetics \& Development 16 143-150. (doi:10.1016/j.gde.2006.02.013)

Hugosson J, Carlsson S, Aus G, Bergdahl S, Khatami A, Lodding P, Pihl CG, Stranne J, Holmberg E \& Lilja H 2010 Mortality results from the Göteborg randomised population-based prostate-cancer screening trial. Lancet Oncology 11 725-732. (doi:10.1016/S1470-2045(10)70146-7)

Kim J, Lee JH \& Iyer VR 2008 Global identification of Myc target genes reveals its direct role in mitochondrial biogenesis and its E-box usage in vivo. PLoS ONE 3 e1798. (doi:10.1371/journal.pone.0001798)

Kirschmann DA, Seftor EA, Nieva DR, Mariano EA \& Hendrix MJ 1999 Differentially expressed genes associated with the metastatic phenotype in breast cancer. Breast Cancer Research and Treatment 55 127-136. (doi:10.1023/A:1006188129423)

Kirschmann DA, Lininger RA, Gardner LM, Seftor EA, Odero VA, Ainsztein AM, Earnshaw WC, Wallrath LL \& Hendrix MJ 2000 Down-regulation of HP1Hsalpha expression is associated with the metastatic phenotype in breast cancer. Cancer Research $603359-3363$.

Kwon SH \& Workman JL 2011 The changing faces of HP1: from heterochromatin formation and gene silencing to euchromatic gene expression: HP1 acts as a positive regulator of transcription. BioEssays 33 280-289. (doi:10.1002/bies.201000138)

Li Z, Van Calcar S, Qu C, Cavenee WK, Zhang MQ \& Ren B 2003 A global transcriptional regulatory role for c-Myc in Burkitt's lymphoma cells. PNAS 100 8164-8169. (doi:10.1073/pnas.1332764100)

Nielsen AL, Ortiz JA, You J, Oulad-Abdelghani M, Khechumian R, Gansmuller A, Chambon P \& Losson R 1999 Interaction with members of the heterochromatin protein 1 (HP1) family and histone deacetylation are differentially involved in transcriptional silencing by members of the TIF1 family. EMBO Journal 18 6385-6395. (doi:10.1093/emboj/ 18.22.6385)

Norwood LE, Moss TJ, Margaryan NV, Cook SL, Wright L, Seftor EA, Hendrix MJ, Kirschmann DA \& Wallrath LL 2006 A requirement for dimerization of HP1Hsalpha in suppression of breast cancer invasion. Journal of Biological Chemistry 281 18668-18676. (doi:10.1074/ jbc.M512454200)

Oberley MJ, Inman DR \& Farnham PJ 2003 E2F6 negatively regulates BRCA1 in human cancer cells without methylation of histone $\mathrm{H} 3$ on lysine 9. Journal of Biological Chemistry 278 42466-42476. (doi:10.1074/ jbc.M307733200)

Piacentini L, Fanti L, Berloco M, Perrini B \& Pimpinelli S 2003 Heterochromatin protein 1 (HP1) is associated with induced gene expression in Drosophila euchromatin. Journal of Cell Biology $\mathbf{1 6 1}$ 707-714. (doi:10.1083/jcb.200303012)

Pomeroy SL, Tamayo P, Gaasenbeek M, Sturla LM, Angelo M, McLaughlin ME, Kim JY, Goumnerova LC, Black PM, Lau C et al. 2002 Prediction of central nervous system embryonal tumour outcome based on gene expression. Nature 415 436-442. (doi:10.1038/415436a)

Ritou E, Bai M \& Georgatos SD 2007 Variant-specific patterns and humoral regulation of HP1 proteins in human cells and tissues. Journal of Cell Science 120 3425-3435. (doi:10.1242/jcs.012955)

Ruginis T, Taglia L, Matusiak D, Lee BS \& Benya RV 2006 Consequence of gastrin-releasing peptide receptor activation in a human colon cancer cell line: a proteomic approach. Journal of Proteome Research $\mathbf{5}$ 1460-1468. (doi:10.1021/pr060005g) 
Ryan CJ \& Tindall DJ 2011 Androgen receptor rediscovered: the new biology and targeting the androgen receptor therapeutically. Journal of Clinical Oncology 29 3651-3658. (doi:10.1200/JCO.2011.35.2005)

Schröder FH, Hugosson J, Roobol MJ, Tammela TL, Ciatto S, Nelen V, Kwiatkowski M, Lujan M, Lilja H, Zappa M et al. 2009 Screening and prostate-cancer mortality in a randomized European study. New England Journal of Medicine 360 1320-1328. (doi:10.1056/ NEJMoa0810084)

Schröder FH, Hugosson J, Roobol MJ, Tammela TL, Ciatto S, Nelen V, Kwiatkowski M, Lujan M, Lilja H, Zappa M et al. 2012 Prostate-cancer mortality at 11 years of follow-up. New England Journal of Medicine 366 981-990. (doi:10.1056/NEJMoa1113135)

Shapiro E, Huang H, Ruoff R, Lee P, Tanese N \& Logan SK 2008 The heterochromatin protein 1 family is regulated in prostate development and cancer. Journal of Urology 179 2435-2439. (doi:10.1016/j.juro.2008. 01.091)

Sharma GG, Hwang KK, Pandita RK, Gupta A, Dhar S, Parenteau J, Agarwal M, Worman HJ, Wellinger RJ \& Pandita TK 2003 Human heterochromatin protein 1 isoforms $\mathrm{HP} 1(\mathrm{Hs} \alpha)$ and $\mathrm{HP} 1(\mathrm{Hs} \beta)$ interfere with hTERT-telomere interactions and correlate with changes in cell growth and response to ionizing radiation. Molecular and Cellular Biology 23 8363-8376. (doi:10.1128/MCB.23.22.8363-8376.2003)

Shigemura K, Sung SY, Kubo H, Arnold RS, Fujisawa M, Gotoh A, Zhau HE \& Chung LW 2007 Reactive oxygen species mediate androgen receptorand serum starvation-elicited downstream signaling of ADAM9 expression in human prostate cancer cells. Prostate 67 722-731. (doi:10.1002/pros.20565)

Shiota M, Song Y, Yokomizo A, Tada Y, Kuroiwa K, Eto M, Oda Y, Inokuchi J, Uchiumi T, Fujimoto N et al. 2010a Human heterochromatin protein 1 isoform HP1 $\beta$ enhances androgen receptor activity and is implicated in prostate cancer growth. Endocrine-Related Cancer 17 455-467. (doi:10.1677/ERC-09-0321)

Shiota M, Yokomizo A, Tada Y, Inokuchi J, Kashiwagi E, Masubuchi D, Eto M, Uchiumi T \& Naito S $2010 b$ Castration resistance of prostate cancer cells caused by castration-induced oxidative stress through Twist1 and androgen receptor overexpression. Oncogene 29 237-250. (doi:10.1038/onc.2009.322)
Shiota M, Takeuchi A, Song Y, Yokomizo A, Kashiwagi E, Uchiumi T, Kuroiwa K, Tatsugami K, Fujimoto N, Oda Y et al. 2011a Y-box binding protein-1 promotes castration-resistant prostate cancer growth via androgen receptor expression. Endocrine-Related Cancer 18 505-517. (doi:10.1530/ERC-11-0017)

Shiota M, Yokomizo A, Kashiwagi E, Takeuchi A, Fujimoto N, Uchiumi T \& Naito S 2011b Peroxiredoxin 2 in the nucleus and cytoplasm distinctly regulates androgen receptor activity in prostate cancer cells. Free Radical Biology \& Medicine 51 78-87. (doi:10.1016/j.freeradbiomed. 2011.04.001)

Siegel R, Naishadham D \& Jemal A 2012 Cancer statistics, 2012. CA: A Cancer Journal for Clinicians 62 10-29. (doi:10.3322/caac.20138)

Takanashi M, Oikawa K, Fujita K, Kudo M, Kinoshita M \& Kuroda M 2009 Heterochromatin protein $1 \gamma$ epigenetically regulates cell differentiation and exhibits potential as a therapeutic target for various types of cancers. American Journal of Pathology 174 309-316. (doi:10.2353/ ajpath.2009.080148)

Wasenius VM, Hemmer S, Kettunen E, Knuutila S, Franssila K \& Joensuu H 2003 Hepatocyte growth factor receptor, matrix metalloproteinase-11, tissue inhibitor of metalloproteinase-1, and fibronectin are up-regulated in papillary thyroid carcinoma: a cDNA and tissue microarray study. Clinical Cancer Research 9 68-75.

Weinmann AS, Yan PS, Oberley MJ, Huang TH \& Farnham PJ 2002 Isolating human transcription factor targets by coupling chromatin immunoprecipitation and CpG island microarray analysis. Genes and Development 16 235-244. (doi:10.1101/gad.943102)

de Wit E, Greil F \& van Steensel B 2007 High-resolution mapping reveals links of HP1 with active and inactive chromatin components. PLoS Genetics 3 e38. (doi:10.1371/journal.pgen.0030038)

Zarebski M, Wiernasz E \& Dobrucki JW 2009 Recruitment of heterochromatin protein 1 to DNA repair sites. Cytometry. Part A 75 619-625. (doi:10.1002/cyto.a.20734)

Zhang R \& Adams PD 2007 Heterochromatin and its relationship to cell senescence and cancer therapy. Cell Cycle 6 784-789. (doi:10.4161/ cc.6.7.4079)

Zhao T, Heyduk T, Allis CD \& Eissenberg JC 2000 Heterochromatin protein 1 binds to nucleosomes and DNA in vitro. Journal of Biological Chemistry 275 28332-28338. (doi:10.1074/jbc.M003493200)

Received in final form 16 March 2013

Accepted 27 March 2013

Accepted Preprint published online 27 March 2013 http://jme.endocrinology-journals.org DOI: 10.1530/JME-13-0024
C 2013 Society for Endocrinology Printed in Great Britain
Published by Bioscientifica Ltd. 